\title{
Diagnostic and Classification Considerations Related to Compulsive Sexual Behavior Disorder and Problematic Pornography Use
}

\author{
Stephanie Antons ${ }^{1}$ D $\cdot$ Matthias Brand ${ }^{1,2}$ \\ Accepted: 21 June 2021 / Published online: 9 July 2021 \\ (C) The Author(s) 2021
}

\begin{abstract}
Purpose of Review There are ongoing debates about specific features of compulsive sexual behavior disorder (CSBD) relating to classification and diagnoses. We aim to address current discussions relating to potential subtypes of CSBD, the aspect of compulsivity in CSBD, and the aspect of moral incongruence and CSBD.

Recent Findings CSBD includes multiple specific sexual behaviors that might be related to specific psychological processes. Problematic pornography use may be considered a subtype of CSBD, which may have multiple parallels with addictive behaviors. The feature of compulsivity in CSBD may be different from compulsivity in other disorders and may be differently involved in early versus later stages of CSBD. Moral incongruence is important to consider in the context of CSBD, although moral disapproval is not a general exclusion criterion for diagnosing CSBD.

Summary Considering the current debates of specific features of CSBD, future research and clinical practice may benefit from a trans-diagnostic approach to contribute to a more fine-grained understanding of the multiple facets of CSBD.
\end{abstract}

Keywords Hypersexuality $\cdot$ Sex addiction $\cdot$ Porn addiction $\cdot$ ICD-11

\section{Introduction}

Compulsive sexual behavior disorder (CSBD) has been included in the eleventh revision of the International Classification of Diseases (ICD-11) as an impulse control disorder [1]. Individuals suffering from CSBD experience marked distress or significant impairment in important areas of functioning for an extended period of time ( 6 month or more) due to a "persistent pattern of failure to control intense, repetitive sexual impulses, or urges resulting in repetitive sexual behavior." Further symptoms may be that the sexual behaviors become central focus of the person's life to the point of neglecting other important activities (heath care, interests, activities, responsibilities), numerous

This article is part of the Topical Collection on Sex \& Addiction

Stephanie Antons stephanie.antons@uni-due.de

1 General Psychology: Cognition and Center for Behavioral Addiction Research (CeBAR), University of Duisburg, Forsthausweg 2, 47057 Duisburg, Germany

2 Erwin L. Hahn Institute for Magnetic Resonance Imaging, Essen, Germany unsuccessful attempts to reduce the behavior, and the continuation of the sexual behaviors despite experiencing negative consequences or deriving little or no satisfaction from the behavior. The criterion of distress is not sufficiently met, if the distress is entirely related to moral judgments and disapproval about the sexual behavior, urges, or impulses. In addition, paraphilic disorders are excluded from the diagnosis of CSBD.

The classification of CSBD has been recognized as an important step towards addressing clinical needs of patients, to empower clinicians in their work treating patients with CSBD, and also for scientists who study psychological and neurobiological mechanisms of CSBD to improve treatment and prevention [2]. Nevertheless, there are still some open questions regarding specific definitions within the classification and the practical application of single criteria, which we aim to address in this contribution.

Within the classification in the ICD-11, the umbrella term "sexual behaviors" is used. Although sexual behaviors subsume many heterogenous behaviors, there are especially two streams of research on CSBD: those addressing sexual behaviors in general and those addressing specifically pornography use. Therefore, we first aim to comment on the questions (1) Which specific sexual behaviors are meant in the definition of CSBD? Relatedly, is problematic pornography use adequately 
subsumed under this umbrella term? Further, we aim to comment on the "compulsive" aspect in the diagnosis of CSBD by addressing the question (2) How much compulsivity is included in CSBD, which also means how compulsive is CSBD as an impulse control disorder? Finally, the consideration of distress that is entirely related to a discrepancy between beliefs about pornography use (i.e., that it is wrong) and the behavior itself - often described as moral incongruence [3, 4] — within the diagnostic procedure is an important aspect to avoid a pathologization of unproblematic sexual behaviors. From a practical point of view, however, it is unclear how this limitation of the criterion of distress has (or should have) an impact on the diagnosis of CSBD. Therefore, we further aim to comment on the question (3) Which effect does the consideration of distress that is entirely related to moral incongruencies have on clinical practice and research?

\section{Which Specific Sexual Behaviors Are Meant in the Definition of Compulsive Sexual Behavior Disorders? Relatedly, Is Problematic Pornography Use Adequately Subsumed Under this Umbrella Term?}

Studies report a high heterogeneity with regard to sexual behaviors shown by individuals with CSBD [5]. These include masturbation, pornography use, phone sex, cybersex, visiting strip clubs, paid sexual services, excessive fantasizing about sex and sex practices, and sex with consenting adults $[6,7 \bullet, 8,9]$. Although masturbation, pornography use, using cybersex, having multiple sexual partners, and searching sexual fantasies are the behaviors reported predominantly by individuals with CSBD [9], the behaviors that are most often described as problematic for individuals with CSBD are unsatisfying or unprotected sexual intercourse and having multiple sexual partners. Probably, individuals with CSBD experience the most explicit negative consequences (e.g., problems with partners or sexual infectious diseases) due to the latter behaviors although the former behaviors may be those with which individuals with CSBD spend most of time. It is possible that negative consequences due to these behaviors only slowly become apparent. Some individuals with CSBD may experience problems only due to one single behavior (e.g., only pornography use), there may be more individuals experiencing problems due to multiple behaviors [5]. Less is known on the specific effects of certain sexual behaviors, however, recognizing the heterogeneity of different behaviors in CSBD may be important to understand the etiology of specific types of CSBD and to develop specific treatment approaches, which might be different for those reporting problems related specifically to pornography use than for individuals experiencing problems related to multiple specific sexual behaviors $[10,11]$.

Preferences for specific sexual behaviors may result from individual motives and use expectancies that are satisfied by specific characteristics of the sexual behaviors. For example,
Cooper [12] emphasized, from a media psychological perspective, that the appeal of online sexual behaviors, in contrast to offline sexual behaviors, results from the unlimited and fast access, high affordability, and high anonymity. These characteristics may not only ease the satisfaction of psychological needs or coping with negative mood, such as loneliness [13], sexual desires [14], or emotional-avoidance [15, 16]; they may also affect central affective and cognitive mechanisms, which contribute to the addictive potential of online sexual activities. For example, in early stages of the problematic behavior, it can be assumed that online sexual behaviors result in the experience of gratification when psychological needs and desires are satisfied [17]. The repeated use of online sexual materials may, however, intensify processes of cue-reactivity and craving $[18,19]$ especially due to the fact that online sexual material such as pornography is accessible from everywhere and at any time. Therefore, individuals may be more often confronted with distal or proximal cues associated with online sexual behaviors which may increase the urge to use online sexual material and which may result in diminished control over the behavior. In addition to the fact that such situations may occur more often they may also be less avoidable than situations associated with offline sexual activities (e.g., visiting a strip club). Similarly, the high affordability (low costs and low access barriers) may decrease the subjective value of immediate negative consequences which may result in more disadvantageous decision making and reduced inhibitory control processes $[18,20]$. Also, the high anonymity during online sexual activities reduces access barriers, negative consequences, and hesitations that may be present in the direct contact with others during offline sexual activities [12]. Thus, the barriers for the behavior to become a habit and to escalate in later stages of the disorder are low which may segregate in higher frequencies and duration of use as well as variability of the used online sexual materials $[18,21 \cdot]$. Differences in associations between features of CSBD (e.g., impulsivity) and symptom severity of CSBD or problematic pornography use [22.] may be indicators for the involvement of (slightly) different psychological processes depending on the specific sexual behavior. In addition, some sexual behaviors may have stronger effects on individuals with certain characteristics (e.g., gender effects) [23].

As such, online sexual behaviors and offline sexual behaviors may affect core psychological mechanisms differently, which may make a differentiation reasonable, especially when it comes to aspects of treatment. Therefore, more research is needed with regard to the effects of specific characteristics of sexual behaviors on psychological mechanisms of the development and maintenance of CSBD.

\section{How Much Compulsivity Is Included in CSBD?}

Within the ICD-11 classification it has been decided to use the term compulsive sexual behavior disorder. Following 
Fineberg and collegues, a certain behavior can be defined as compulsive when it is characterized as "performance of repetitive and functionally impairing overt or covert behavior without adaptive function, performed in a habitual or stereotyped fashion, either according to rigid rules or as a means of avoiding perceived negative consequences" [24, p. 2].

We will now take serially different aspects of this definition into account to evaluate whether these aspects of the compulsivity definition seem to be valid for CSBD. The first aspect is that the behavior is without adaptive functions. Concerning sexual behaviors in general, most individuals perform sexual behaviors even repetitively in an adaptive way with the goal to experience gratification (e.g., satisfaction of sexual needs, attachment to others) [25] or to cope with positive or negative emotions (happiness, stress, loneliness) [26, 27]. This adaptive function of sexual behaviors (e.g., changing the mood beyond the more global evolutionary adaptive functions of sexual behaviors) may be also present in individuals with higher symptom severity of CSBD as shown by Laier and Brand [28] in the context of problematic pornography use. Accordingly, sexual behaviors may be functionally adaptive in the first place, but may interfere with functioning in several domains of life in the longer outcome. Case reports indicate that when individuals with CSBD reflect on their (excessive) sexual behaviors they are often aware of possible negative consequences of the behavior but that they are not able to stop or reduce it [10]. Further, it has been shown that the attitude towards pornography is more negative in individuals with problematic pornography use compared to those with recreational pornography use [18]. Accordingly, it may come to situations typical for compulsive behaviors where individuals behave sexually while they are aware that this behavior is not in line with his or her overall goals [29]. The sexual behavior may nevertheless have an adaptive function (in contrast to compulsive behaviors), at least in earlier stages of CSBD.

The next element of the definition of compulsive behaviors by Fineberg et al. [24] is that the behavior is in a habitual or stereotyped fashion and that individuals often follow rigid rules. For CSBD this would mean, for example, that individuals always used pornography at the same time, the same place, or in the same sequence following specific rules. This may also include that the individual looked the same pornographic content or that the behavior follows other specific rules. However, case reports indicate that rigid rules are less important in CSBD [10]. Instead, individuals seem to prefer adventurous sexual activities and new sexual online material [10]. This might be an important difference between obsessive-compulsive behaviors such as skin picking, washing or checking, and CSBD.

The last aspect of the definition of compulsive behaviors is the driving motivation of avoiding negative feelings and consequences which are anticipated to occur if individuals would not behave in a specific rule-guided way (e.g., contamination if washing hands would not be possible). Compulsive behaviors are often motivated by harm-avoidance while impulsive behaviors are most often motivated by gratification and riskseeking [24]. As mentioned above, one central causality in compulsive behaviors is to avoid harm by executing the specific behavior and that the individuals expect negative consequences if they would not behave specifically. This should be differentiated from the execution of the specific behavior to cope with negative emotions that are not directly related to not behaving in a specific manner. The gratifying effect of most sexual behaviors may indicate that - at least in early stages of CSBD - the experience of reward is in focus of the behavior and not avoidance of harm that would occur if the individuals would not behave sexually. (With regard to the previous section, we want to add here that the rewarding effect of specific sexual behaviors may vary and differently contribute to mechanisms of the development and maintenance of CSBD). Increases in symptom severity may also be associated with diminishing pleasurable effects of the sexual behavior and increased behavior to avoid negative mood or to cope with stress and negative feelings [30]. The review by LewStarowicz et al. [27] shows that in later stages of CSBD (meaning in individuals who already experience negative consequences due to the behavior) especially coping with negative mood becomes a central motivation of the sexual behaviors. In addition, a longitudinal study could show that impulsivity at baseline significantly predicted pornography use frequency but not symptom severity 2 years later [31]. In sum, CSBD is probably motivated by the experience of gratification in early stages. In later stages, the compensatory effects for negative emotions and stress may become a central motive for executing the sexual behaviors. As in many addictions as well and described in the Incentive-Sensitization Theory, this development from "liking" (behavior motivated by reward) in early stages to "wanting" (habitual behavior and behavior motivated by avoiding harm) may be an important characteristic of CSBD [32,33]. Therefore, "compulsive" may be adequate to describe the sexual behaviors in later stages, but this does not include compulsivity in earlier stages, when the rewarding aspect seems to be central, although the sexual behaviors may already cause distress.

Except for the fact that sexual behavior can have compulsive facets, we know very little about the "real" compulsiveness of CSBD. In addition, there have been two issues with the assessment of compulsivity in CSBD: (1) the measures of compulsivity have been non-trans-diagnostic [34] and (2) as it has been shown for impulsivity before [35], measuring a kind of trait compulsivity may say less about whether the sexual behavior itself is compulsive. Considering the first issue, compulsivity in CSBD has been investigated in few studies and in the studies where it has been investigated, it was only indirectly measured by assessing the co-morbidity or symptoms of other compulsive behaviors [22•, 36-38]. This 
however, does not assess compulsivity as trait variable and trans-diagnostic feature of multiple mental disorder such as obsessive-compulsive disorders and addiction [34, 39]. Future research should investigate compulsivity as a transdiagnostic and dimensional trait variable that contributes to the development and maintenance of CSBD. Coming to the second issue, measuring behavior-unrelated compulsivity may be uninformative on the compulsive nature of sexual behaviors in CSBD itself. Based on the experience with impulsivity $[35,40]$, it may be possible that although some facets of compulsivity may be quite stable (trait) within an individual, other facets may fluctuate with regard to specific behaviors. For example, an individual may behave compulsively with regard to eating but less compulsive with regard to pornography use. Accordingly, it may be also helpful for the understanding of CSBD to measure the degree of compulsiveness of the concrete sexual behaviors of an individualmeaning behavior-related compulsivity. This may be done by an evaluation of criteria mentioned in the definition by Fineberg et al. [24] specifically for the sexual behavior. Another way could be to use tasks measuring compulsive behaviors (e.g., contingency-related cognitive inflexibility, task or attentional shifting, attentional bias or disengagement, or habit learning) while parts of the task are set in the context of sexual behaviors (e.g., by including explicit sexual material) as it was done, for example, in studies on impulsivity in using pornography [41].

The level of compulsivity in CSBD and its occurrence in different stages of the disorder is not only a question of classification or label. Previous works on addiction have shown that different types of craving that can be aligned to characteristics of impulsive and compulsive behaviors are evoked by different neuroendocrine processes [42]. It is assumed that reward craving, the desire for the rewarding, stimulating, or enhancing effects of the behavior, arises from dysfunctions within dopaminergic/opioideric systems. Relief craving, the desire for the reduction of tension or arousal, may result from dysfunctions within GABAeric/glutamateric systems. Obsessive craving, the desire resulting from the lack of control over intrusive thoughts about the behavior, may arise from dysregulations of serotonin. Following on this, the identification of the level of compulsiveness in different stages of CSBD and the existence of different forms of craving may be substantial for improving treatment strategies for CSBD [43].

\section{Which Effect Does the Consideration of Distress that Is Entirely Related to Moral Incongruencies Has on Clinical Practice and Research?}

We now want to comment on the final sentences within the current definition of CSBD in the ICD-11: "The pattern of failure to control intense, sexual impulses or urges, and resulting repetitive sexual behavior is manifested over an extended period of time (e.g., 6 months or more) and causes marked distress or significant impairment in personal, family, social, educational, occupational, or other important areas of functioning. Distress that is entirely related to moral judgments and disapproval about sexual impulses, urges, or behaviors is not sufficient to meet this requirement". First, it has to be highlighted that experiencing distress or significant functional impairment is a basic requirement for the diagnosis of CSBD - as it is in many other disorders including addictive behaviors, for example, gambling and gaming disorders. Second, the OR connection is important here which means that individuals do not need to experience both distress and functional impairment. Third, the limitation in the case of a general moral disapproval of sexual behaviors, impulses, or urges only relate to the distress criterion, not to the criterion of functional impairment. Accordingly, individuals who entirely experience distress due to general disapproval (e.g., moral incongruence) but also experience negative consequences due to the sexual behavior can be diagnosed with CSBD without reservation. Fourth, the criterion of distress can also be sufficiently met if individuals experience distress due to a general disapproval and due to other factors, since it is in this case not "entirely" caused by general disapproval. These considerations show that both clinicians and researchers are required to explicitly ask for specific reasons of distress and negative consequences.

The topic of moral incongruence in the context of selfperceived addictive pornography use has received much attention $[4,44,45]$. It has been argued that within the diagnostic process, moral incongruence related to pornography use is important to consider. However, this does not mean that as soon as individuals with self-perceived addictive use of pornography express that the pornography use violates moral values cannot be diagnosed with CSBD and therefore cannot ask for specific treatments. For example, an individual reporting that he/she experiences intensive distress entirely due to the incongruence between the content of pornographic material and religious values but he/she does not experience other negative consequences, this individual should be treated for example with Acceptance and Commitment Therapy techniques [44], that teaches individuals to accept their feelings (e.g., of moral incongruence) and to change the way how they interact with or relate to these thoughts [46]. On the other hand, if an individual reports distress due to moral incongruence but also experiences negative consequences due to the sexual behaviors (e.g., losing his/her job because of viewing pornography at work), and gives increasing priority to sexual behaviors, which are difficult to control, treatments including behavior modification and other techniques of cognitive behavioral therapy might be important to regain control over the behavior [45]. 


\section{Conclusion}

In research and clinical practice, we should ask which sexual behaviors are problematic for individuals with CSBD in order to better understand potentially varying processes in the development and maintenance of the problematic sexual behaviors and to offer individualized and specified treatment and intervention. The compulsive nature of CSBD with regard to the potentially varying degrees of compulsivity in different stages of CSBD and problematic pornography use needs to be further investigated in future research. This should include trans-diagnostic trait approaches targeting impulsivity and compulsivity. In CSBD, the factors that cause marked distress are highly relevant for the diagnosis. Accordingly, there is a high need to evaluate them within diagnostic interviews and screenings. With the classification of CSBD within the ICD11 a very important first step was taken. This development has inspired further important discussions of how to diagnose CSBD most appropriately (including new screening instruments and guidelines for clinical interviews). Given that we now have the definition of diagnostic criteria, we will be able to better estimate the prevalence rates and to systematically gain a better understanding of the processes underlying CSBD and potentially subtypes of CSBD, for example problematic pornography use. The questions and speculations that we have summarized in this manuscript may inspire research to contribute to a more fine-grained understanding of the multiple facets of CSBD.

Acknowledgements The work on this article was carried out in the context of the Research Unit ACSID, FOR2974, funded by the Deutsche Forschungsgemeinschaft (DFG, German Research Foundation) 411232260 .

Author Contributions SA and MB conceptualized the manuscript. SA drafted the manuscript. MB supervised the writing of the manuscript and critically revised the work. The final draft was discussed and approved by all co-authors.

Funding Open Access funding enabled and organized by Projekt DEAL.

\section{Declarations}

Conflict of Interest The authors declare that they have no conflict of interest.

Open Access This article is licensed under a Creative Commons Attribution 4.0 International License, which permits use, sharing, adaptation, distribution and reproduction in any medium or format, as long as you give appropriate credit to the original author(s) and the source, provide a link to the Creative Commons licence, and indicate if changes were made. The images or other third party material in this article are included in the article's Creative Commons licence, unless indicated otherwise in a credit line to the material. If material is not included in the article's Creative Commons licence and your intended use is not permitted by statutory regulation or exceeds the permitted use, you will need to obtain permission directly from the copyright holder. To view a copy of this licence, visit http://creativecommons.org/licenses/by/4.0/.

\section{References}

Papers of particular interest, published recently, have been highlighted as:

- Of importance

•• Of major importance

1. World Health Organization. (2020). International statistical classification of diseases and related health problems (11th Revision). Retrieved from https://icd.who.int/browse11/1-m/en. Accessed 9 Apr 2021.

2. Gola M, Potenza MN. Promoting educational, classification, treatment, and policy initiatives: Commentary on: Compulsive sexual behaviour disorder in the ICD-11 (Kraus et al., 2018). J Behav Addict. 2018. https://doi.org/10.1556/2006.7.2018.51.

3. Grubbs JB, Kraus SW, Perry SL. Self-reported addiction to pornography in a nationally representative sample: the roles of use habits, religiousness, and moral incongruence. J Behav Addict. 2019. https://doi.org/10.1556/2006.7.2018.134.

4. Lewczuk K, Glica A, Nowakowska I, Gola M, Grubbs JB. Evaluating pornography problems due to moral incongruence model. J Sex Med. 2020. https://doi.org/10.1016/j.jsxm.2019.11.259.

5. Derbyshire KL, Grant JE. Compulsive sexual behavior: a review of the literature. J Behav Addict. 2015. https://doi.org/10.1556/2006. 4.2015.003.

6. Reid RC, Carpenter BN, Hook JN, Garos S, Manning JC, Gilliland R, et al. Report of findings in a DSM-5 field trial for hypersexual disorder. J Sex Med. 2012. https://doi.org/10.1111/j.1743-6109.2012.02936.x.

7. Castro-Calvo J, Gil-Llario MD, Gimenez-Garcia C, Gil-Julia B, Ballester-Arnal R. Occurrence and clinical characteristics of Compulsive Sexual Behavior Disorder (CSBD): a cluster analysis in two independent community samples. J Behav Addict. 2020. https://doi.org/10.1556/2006.2020.00025 Important study describing the occurrence and clinical profile of individuals with CSBD based on the ICD-11 criteria.

8. Kowalewska E, Kraus SW, Lew-Starowicz M, Gustavsson K, Gola $\mathrm{M}$. Which dimensions of human sexuality are related to compulsive sexual behavior disorder (CSBD)? Study using a multidimensional sexuality questionnaire on a sample of polish males. J Sex Med. 2019. https://doi.org/10.1016/j.jsxm.2019.05.006.

9. Wéry A, Vogelaere K, Challet-Bouju G, Poudat FX, Caillon J, Lever D, et al. Characteristics of self-identified sexual addicts in a behavioral addiction outpatient clinic. J Behav Addict. 2016. https://doi.org/10.1556/2006.5.2016.071.

10. Cantor JM, Klein C, Lykins A, Rullo JE, Thaler L, Walling BR. A treatment-oriented typology of self-identified hypersexuality referrals. Arch Sex Behav. 2013. https://doi.org/10.1007/s10508-013-0085-1.

11. Walton MT, Bhullar N. The "msychology" of hypersexuality: a 40year-old bisexual man's use of online chat, pornography, masturbation, and extradyadic sex. Arch Sex Behav. 2018. https://doi.org/ 10.1007/s10508-018-1274-8.

12. Cooper A. Sexuality and the Internet: surfing into the new millennium. CyberPsychol Behav. 1998. https://doi.org/10.1089/cpb. 1998.1.187.

13. Efrati Y, Gola M. Understanding and predicting profiles of compulsive sexual behavior among adolescents. J Behav Addict. 2018. https://doi.org/10.1556/2006.7.2018.100.

14. Varfi N, Rothen S, Jasiowka K, Lepers T, Bianchi-Demicheli F, Khazaal Y. Sexual desire, mood, attachment style, impulsivity, and self-esteem as predictive factors for addictive cybersex. J Med Internet Res - Ment Health. 2019. https://doi.org/10.2196/mental.9978.

15. Baranowski AM, Vogl R, Stark R. Prevalence and determinants of problematic online pornography use in a sample of German women. J Sex Med. 2019. https://doi.org/10.1016/j.jsxm.2019.05.010. 
16. Engel J, Veit M, Sinke C, Heitland I, Kneer J, Hillemacher T, et al. Same same but different: a clinical characterization of men with hypersexual disorder in the Sex@Brain Study. J Clin Med. 2019. https://doi.org/10.3390/jcm8020157.

17. Cooper A, Morahan-Martin J, Mathy RM, Maheu M. Toward an increased understanding of user demographics in online sexual activities. J Sex Marital Ther. 2002. https://doi.org/10.1080/ 00926230252851861.

18. Antons S, Müller SM, Wegmann E, Trotzke P, Schulte MM, Brand M. Facets of impulsivity and related aspects differentiate among recreational and unregulated use of Internet pornography. J Behav Addict. 2019. https://doi.org/10.1556/2006.8.2019.22.

19. Berridge $\mathrm{KC}$, Robinson TE. Liking, wanting and the incentivesensitization theory of addiction. Am Psychol. 2016. https://doi. org/10.1037/amp0000059.

20. Castro-Calvo J, Cervigón-Carrasco V, Ballester-Arnal R, GiménezGarcía C. Cognitive processes related to problematic pornography use (PPU): a systematic review of experimental studies. Addict Behav Rep. 2021. https://doi.org/10.1016/j.abrep.2021.100345.

21. Lewczuk K, Lesniak J, Lew-Starowicz M, Gola M. Variability of pornographic content consumed and longest session of pornography use associated with treatment seeking and problematic sexual behavior symptoms. Sex Med. 2021. https://doi.org/10.1016/j. esxm.2020.10.004 First study investigating th variability of pornographic content in individuals with CSBD.

22. Böthe B, Tóth-Király I, Orosz G, Potenza MN, Griffiths MD, Demetrovics Z. Revisiting the role of impulsivity and compulsivity in problematic sexual behaviors. J Sex Res. 2018. https://doi.org/ $10.1080 / 00224499.2018 .1480744$ Important study showing that impulsivity and compulsivity may contribute differently to CSB and problematic pornography use.

23. Bőthe B, Koós M, Tóth-Király I, Orosz G, Demetrovics Z. Investigating the associations of adult ADHD symptoms, hypersexuality, and problematic pornography use among men and women on a largescale, non-clinical sample. J Sex Med. 2019. https://doi. org/10.1016/j.jsxm.2019.01.312.

24. Fineberg NA, Chamberlain SR, Goudriaan AE, Stein DJ, Vanderschuren LJMJ, Gillan CM, et al. New developments in human neurocognition: clinical, genetic, and brain imaging correlates of impulsivity and compulsivity. CNS Spectr. 2014. https://doi.org/ 10.1017/S1092852913000801.

25. Grubbs JB, Kraus SW. Pornography use and psychological science: A call for consideration. Curr Dir Psychol Sci. 2021. https://doi.org/ 10.1177/0963721420979594.

26. Black DW, Kehrberg LL, Flumerfelt DL, Schlosser SS. Characteristics of 36 subjects reporting compulsive sexual behavior. Am J Psychiatry. 1997. https://doi.org/10.1176/ajp.154.2.243.

27. Lew-Starowicz M, Lewczuk K, Nowakowska I, Kraus S, Gola M. Compulsive sexual behavior and dysregulation of emotion. Sex Med Rev. 2020. https://doi.org/10.1016/j.sxmr.2019.10.003.

28. Laier C, Brand M. Mood changes after watching pornography on the Internet are linked to tendencies towards Internet-pornographyviewing disorder. Addict Behav Rep. 2017. https://doi.org/10.1016/ j.abrep.2016.11.003.

29. Luigjes J, Lorenzetti V, de Haan S, Youssef GJ, Murawski C, Sjoerds Z, et al. Defining compulsive behavior. Neuropsychol Rev. 2019. https://doi.org/10.1007/s11065-019-09404-9.

30. Gola M, Lewczuk K, Potenza MN, Kingston DA, Grubbs JB, Stark $\mathrm{R}$, et al. What should be included in the criteria for compulsive sexual behavior disorder? J Behav Addict. 2020. https://doi.org/ 10.1556/2006.2020.00090.

31. Rousseau A, Bothe B, Stulhofer A. Theoretical antecedents of male adolescents' problematic pornography use: a longitudinal assessment. J Sex Res. 2021. https://doi.org/10.1080/00224499.2020.1815637.
32. Everitt BJ, Robbins TW. Drug addiction: updating actions to habits to compulsions ten years on. Annu Rev Psychol. 2016. https://doi. org/10.1146/annurev-psych-122414-033457.

33. Brand M, Wegmann E, Stark R, Müller A, Wölfling K, Robbins TW, et al. The Interaction of Person-Affect-Cognition-Execution (I-PACE) model for addictive behaviors: update, generalization to addictive behaviors beyond Internet-use disorders, and specification of the process character of addictive behaviors. Neurosci Biobehav Rev. 2019. https:// doi.org/10.1016/j.neubiorev.2019.06.032.

34. Chamberlain SR, Grant JE. Initial validation of a transdiagnostic compulsivity questionnaire: the Cambridge-Chicago Compulsivity Trait Scale. CNS Spectr. 2018. https://doi.org/10.1017/ s1092852918000810.

35. Wiers RW, Ames S, Hofmann W, Krank M, Stacy A. Impulsivity, impulsive and reflective processes and the development of alcohol use and misuse in adolescents and young adults. Front Psychol. 2010. https://doi.org/10.3389/fpsyg.2010.00144.

36. Fuss J, Briken P, Stein DJ, Lochner C. Compulsive sexual behavior disorder in obsessive-compulsive disorder: prevalence and associated comorbidity. J Behav Addict. 2019. https://doi.org/10.1556/ 2006.8.2019.23

37. Levi G, Cohen C, Kaliche S, Sharaabi S, Cohen K, Tzur-Bitan D, et al. Sexual addiction, compulsivity, and impulsivity among a predominantly female sample of adults who use the internet for sex. J Behav Addict. 2020. https://doi.org/10.1556/2006.2020.00007.

38. Raymond NC, Coleman E, Miner MH. Psychiatric comorbidity and compulsive/impulsive traits in compulsive sexual behavior. Compr Psychiatry. 2003. https://doi.org/10.1016/S0010-440X(03)00110$\mathrm{X}$.

39. Hook RW, Grant JE, Ioannidis K, Tiego J, Yücel M, Wilkinson P, et al. Trans-diagnostic measurement of impulsivity and compulsivity: a review of self-report tools. Neurosci Biobehav Rev. 2021. https://doi.org/10.1016/j.neubiorev.2020.10.007.

40. Jones A, Christiansen P, Nederkoorn C, Houben K, Field M. Fluctuating disinhibition: implications for the understanding and treatment of alcohol and other substance use disorders. Front Psychiatry. 2013. https://doi.org/10.3389/fpsyt.2013.00140.

41. Antons S, Brand M. Trait and state impulsivity in males with tendency towards Internet-pornography-use disorder. Addict Behav. 2018. https://doi.org/10.1016/j.addbeh.2017.12.029.

42. Verheul R, van den Brink W, Geerlings P. A three-pathway psychobiological model of craving for alcohol. Alcohol Alcohol. 1999. https://doi.org/10.1093/alcalc/34.2.197.

43. Addolorato G, Abenavoli L, Leggio L, Gasbarrini G. How many cravings? Pharmacological aspects of craving treatment in alcohol addiction: a review. Neuropsychobiology. 2005. https://doi.org/10. $1159 / 000084161$.

44. Grubbs JB, Perry SL. Moral incongruence and pornography use: a critical review and integration. J Sex Res. 2019. https://doi.org/10. 1080/00224499.2018.1427204.

45. Brand M, Antons S, Wegmann E, Potenza MN. Theoretical assumptions on pornography problems due to moral incongruence and mechanisms of addictive or compulsive use of pornography: are the two "conditions" as theoretically distinct as suggested? Arch Sex Behav. 2018. https://doi.org/10.1007/s10508-018-1293-5.

46. Hayes SC, Luoma JB, Bond FW, Masuda A, Lillis J. Acceptance and commitment therapy: model, processes and outcomes. Behav Res Ther. 2006. https://doi.org/10.1016/j.brat.2005.06.006.

Publisher's Note Springer Nature remains neutral with regard to jurisdictional claims in published maps and institutional affiliations. 